\title{
SLC1A3 C3590T but not BDNF G196A is a predisposition factor for stress as well as depression, in an adolescent eastern Indian population
}

\author{
Madhumita Ghosh'1 ${ }^{1}$ Akhtar Ali $^{2}$, Shobhna Joshi ${ }^{3}$, Adya Shankar Srivastava ${ }^{4}$ and Madhu G. Tapadia ${ }^{1 *}$ (D)
}

\begin{abstract}
Background: Adolescence is a distinctive stage of various changes and is noted as peak age for onset of many psychiatric disorders, especially linked to stress and depression. Several genetic variations are being increasingly known to be linked with stress and depression. The polymorphisms in two such genes, the BDNF and SLC1A3, have been reported to be linked with either depression/stress or with suicidal behaviour. These genes have not been validated in Indian population, and therefore there is a need to investigate these genes in Indian population. The present study was undertaken to test whether the known polymorphisms SLC1A3 C3590T, SLC1A3 C869G and BDNF G196A are associated or not with stress or depression in an eastern Indian population.

Methods: A case-control association study was performed with 108 cases having variable levels of stress and depression and 205 matched controls. Detection of stress and depression was done by using standard instruments as PSS and CES-D, respectively and demographic profile was obtained for each individual on the basis of personal data sheet. Genotyping for the selected polymorphisms was performed by PCR followed by restriction digestion.

Results: The SNP SLC1A3 C3590T was found to be associated with stress and depression ( $p=0.0042, \mathrm{OR}=2.072$ ). Therefore, the T allele increases the risk by more than two folds for stress and depression in the present population. The other allele of SLC1A3, G869C, as well as BDNF G196A were not associated with stress or depression in the population studied.

Conclusion: SLC1A3 C3590T is a predisposition factor for stress and depression in an eastern Indian population, whereas SLC1A3 G869C and BDNF G196A were not found to be a risk factor. Therefore, presence of T allele of SLC1A3 C3590T, may predict the development of stress and depression in an individual. This may also help in the understanding of pathophysiology of the disease. However, these findings warrant a wider study in Indian populations and would be of significance in understanding the predisposition of stress and depression in this population.
\end{abstract}

Keywords: Depression, Stress, Adolescent, SLCIA3, BDNF, Polymorphism, India

\footnotetext{
* Correspondence: madhu@bhu.ac.in

'Cytogenetics Laboratory, Department of Zoology, Banaras Hindu University, Varanasi 221005, India

Full list of author information is available at the end of the article
}

(c) The Author(s). 2020 Open Access This article is licensed under a Creative Commons Attribution 4.0 International License, which permits use, sharing, adaptation, distribution and reproduction in any medium or format, as long as you give appropriate credit to the original author(s) and the source, provide a link to the Creative Commons licence, and indicate if changes were made. The images or other third party material in this article are included in the article's Creative Commons licence, unless indicated otherwise in a credit line to the material. If material is not included in the article's Creative Commons licence and your intended use is not permitted by statutory regulation or exceeds the permitted use, you will need to obtain permission directly from the copyright holder. To view a copy of this licence, visit http://creativecommons.org/licenses/by/4.0/. The Creative Commons Public Domain Dedication waiver (http://creativecommons.org/publicdomain/zero/1.0/) applies to the data made available in this article, unless otherwise stated in a credit line to the data. 


\section{Introduction}

Stress is considered as a non-specific response of the body to any demand for change [1] or in medical terms any bodily change which causes mental tension; while depression is a mood disorder characterized by low mood, sadness and general loss of interest in life [2]. Adolescence or teenagers (13-21 years of age) is the stage of remarkable physical and behavioural changes in the brain and body and is noted as the peak age of onset for many psychiatric disorders, particularly linked with stress and depression [3]. Nevertheless, most of the teenagers successfully steer this transition stage and become a self-sufficient member of the society. More than one genetic variant(s) in conjunction with environmental factors are likely to increase risk for stress and depression.

Twin studies in past have implicated that heritability of depression ranges from 30 to $40 \%$ indicating a significant level of genetic involvement in the development of stress and depression [4-6]. Several genes and gene families have been scanned for their association with depression and one of them is the SLC1 gene family of solute carriers [7] which encodes the excitatory amino acid transporters (EAAT). In humans, five isoforms of EAATs (EAAT1-5) are known which have different tissue localization. EAAT 1 (coded by SLC1A3 located on chromosome no. 5p13.2) transports glutamate in the brain. Glutamate is a ubiquitous amino acid, which acts as the major excitatory neurotransmitter in numerous projection fibres from cortical and subcortical structures [8], and also plays a crucial role in maintaining the activity of other neurotransmitter systems [9]. It is also recognized that the excitatory properties of glutamate remain under a delicate balance; otherwise it exerts damage or excitotoxicity that can range from cellular malfunction to extensive tissue injury [9]. In brain, specific high affinity glutamate transporters remove glutamate, which ends neurotransmitter activity until the next release of neurotransmitters occur [9]. Disturbance in glutamate uptake from synapses have been linked to reduced sensitivity to feel good, a symptom of depression [10]. Similarly, glutamate receptor AMPA subunit-1 knockout mice showed higher helplessness, lower serotonin and nor-epinephrine levels, disturbed glutamate homeostasis with high glutamate levels and increase in NMDA receptor expression. In ischemia, epilepsy, traumatic brain injury, acute or chronic excitotoxicity associated with the excessive glutamate release is known to be the main cause of tissue damage. GWAS studies conducted for depression in last several years have identified different genetic loci [11], like tSNARE1 [12], and MALDIL1 [13] and several molecular pathways involved in cell adhesion and membrane scaffolding [14]. Microarray analysis has shown considerable reduction in the expression of the members of the SLC1 family of membrane transporters - SLC1A2 and SLC1A3, but increase levels of SLC17A7, in the depression cases compared to controls [15] suggesting their association with occurrence and/or severity of depression. SNP in SLC1A3 C3590T (rs 2269272) is a polymorphism in $3^{\prime}$ UTR, has shown association with suicidal behaviour [16]. The other SNP, SLC1A3 C869G (rs137852619), a missense polymorphism in protein coding region leading to conversion from $\mathrm{C}$ to $\mathrm{G}$ at 869 position, changes proline to arginine and found to be pathogenic, recorded in database but not validated with larger samples. The molecular functioning, genetic interactions and expression profiling of SLC1A3 gene was also studied, but a plausible relationship between sequence variations in SLC1A3 gene and depression, have not been studied so far.

A second important candidate gene is BDNF (brain-derived neurotrophic factor; located on chromosome 11p13) whose molecular pathology has been extensively studied in depression cases [17]. BDNF gene codes for a neurotrophin, which is highly expressed in the central nervous system, particularly in the hippocampus region. It plays elementary role in proliferation, differentiation and survival of neuronal cells, as well as regulating synaptic plasticity and connectivity in the adult brain (memory acquisition and consolidation). The majority of BDNF is secreted via the regulated pathway and is derived from both pre- and postsynaptic sites. A widely accepted "neurotrophic hypothesis", postulates that a reduction in $B D N F$ expression is involved in the pathophysiology of major depression [18], while anti-depressant increases the expression of $B D N F$ in hippocampus [19]. Further, prenatal stress has been shown to alter BDNF expression and signalling [20].

A single nucleotide polymorphism, G196A (rs6265), results in an amino-acid substitution from valine to methionine at codon 66 (Val66Met) in the prodomain of BDNF $[21,22]$. Met allele carriers have shown to exhibit increased harm avoidance and also shows a higher prevalence of depression. A recent review proposed BDNF stress-sensitivity hypothesis which states that disruption of endogenous BDNF activity potentiates sensitivity to stress [23]. Val66Met polymorphism is common in human population; however the allele frequencies have been shown to be varying in specific ethnic backgrounds [24, 25]. A considerably higher frequency of Met allele in poor episodic memory performance, a symptom often observed in subjects with depression [26] and also in stress related psychiatric disorders have been reported [23]. Subsequently, in-vitro analysis in animal models have suggested that 'Met' allele alters the sorting and secretion of proBDNF, such that less regulated (activity dependent) secretion is likely to occur in carriers of at least one 'Met' allele [27]. In spite of the ample evidences, inconsistencies persists [28, 29], in conceding the role of BDNF G196A 
polymorphism with mood disorders, which might also be associated with the lack of statistical power in studies of small sample size, as well as variations across studies in inclusion criteria, such as the definition of psychiatric phenotype [24, 30]. Further, role of sex hormones and various other genetic, hormonal and environmental factors have been implicated in modulating BDNF function $[25,29,31-35]$. Despite a higher risk of depression in Asian and Indian populations [25, 36], extensive studies targeting polymorphisms in $B D N F$ have never been executed in these populations so far.

With the aim to test the hypothesis whether the known polymorphism in two candidate genes:

SLC1A3 (C3590T and C869G) and BDNF (G196A) are associated with stress and depression in adolescent population of eastern Uttar Pradesh (India), a controlcase association study has been undertaken.

\section{Methods and materials Participants}

In the present study, a total of 313 adolescent participants aged 16 to19 years were recruited, out of which 205 were controls with no stress and depression and 108 were the cases having variable degrees of both stress and depression. The recruitment of cases were majorly from Sir Sundarlal Hospital, Banaras Hindu University, a few from Deva Clinic, Kamachha, Varanasi and a few schools chosen for this study. All the participants belong to Eastern Uttar Pradesh, India. Prior to conducting this study approval from ethical committee of Institute of Science, Banaras Hindu University, Varanasi, was taken. A written informed consent from each participant was obtained prior to conduction of the study. A clinical examination was conducted for all participants by a psychiatrist and followed a questionnaire developed from "Percieved stress scale" (PSS) [37] and "Center for epidemiologic Studies Depression" (CES-D) [38], which had major components including: (a) general information; (b) the chief complain (presenting problem(s) and the context in which they occur); c) past history (medical, personal, family histories and premorbid behaviour) d) mental status examination, e) diagnosis according to DSM-5 guidelines [39] and lastly f) treatment plan for the diagnosis of stress and depression.

\section{Diagnosis of stress and depression}

Detection and diagnosis of stress and depression was done according to DSM-V criteria [39] and screening questionnaires, as well as few semi structured questionnaires were administered on adolescents both for stress (PSS) and depression (CES-D).

Stress: The following criteria were used for diagnosis of stress: less/no control over irritation, anger on trivial things, unexpected circumstances makes individual upset, coping failure at work/ home or both, work overload, feeling of being subordinate, feeling nervous /stressed. The scores obtained on these points were computed using standard protocol.

Depression: Clinical depression was diagnosed by a psychiatrist which had the following criteria: Loss/ no interest in work, activity level decreased, increased thoughts of guilt/ worthlessness, disturbed appetite (reduced or increased), sleep duration (reduced or increased), energy levels of body (reduced or increased); impaired/ low concentration, irritable mood and suicidal thoughts or attempts of suicide. The severity level on these parameters was used to calculate the disease-score for each of the participants.

\section{Isolation of DNA from saliva}

Saliva samples of participating adolescents were collected in sterilized vials in $1 \mathrm{X}$ phosphate buffered saline and then kept in $-70{ }^{\circ} \mathrm{C}$ till use. The samples were then thawed, vortexed and pelleted down by centrifugation at $6000 \mathrm{rpm}$ for $5 \mathrm{~min}$ at $4{ }^{\circ} \mathrm{C}$, cells were digested by SDS proteinase $\mathrm{K}$ treatment at $65^{\circ} \mathrm{C}$ and DNA isolation was done following phenol chloroform extraction method as per standard protocol and precipitation by ethanol. DNA was air dried at $37^{\circ} \mathrm{C}$, dissolved in $25 \mu \mathrm{l}$ of 1 XTrisEDTA $(\mathrm{pH}=8.0)$ and was stored at $10^{\circ} \mathrm{C}$. Spectrophotometer (Nanodrop, Thermofisher, ${ }^{\circ}$ USA) was used to check the quality and quantity of DNA.

\section{Genotyping through polymerase chain reaction (PCR) followed by restriction digestion}

Primer 3 (v.0.4.0) (http://bioinfo.ut.ee/primer3-0.4.0/primer3/) and Primer-BLAST (https://www.ncbi.nlm.nih. gov/tools/primer-blast/) tools were used to design region specific primers. In PCR, denaturation was done at $95^{\circ} \mathrm{C}$, primers were annealed at temperatures accordingly (see Table 1) and elongation at $72{ }^{\circ} \mathrm{C}$ for $30 \mathrm{~s}$, this cycle was repeated for 35 cycles. Final extension was carried out at $72^{\circ} \mathrm{C}$ for 3 to $5 \mathrm{~min}$ as required, in thermocycler (ABI, Veriti, $\left.\mathrm{ABI}^{\circ}, \mathrm{CA}, \mathrm{USA}\right)$. Negative template control was taken without DNA for ensuring no contamination. The PCR products were checked on $2 \%$ agarose gel to ensure correct amplicon size. Desired endonucleases as NlaIII (NEB', CA, USA) for BDNF G196A, PflF1(NEB ${ }^{\circ}, \mathrm{CA}$, USA) for SLC1A3 C3590T and BstU1(NEB ${ }^{\circ}$, CA, USA) for SLC1A3 G869C were used for digestion of PCR products for genotyping as indicated in Table 2. After digestion the reaction was stopped by adding1 $1 \mu \mathrm{l} 0.5 \mathrm{~N}$ EDTA and finally the digested products were checked on $4 \%$ agarose gel by electrophoresis.

\section{Statistical analysis}

Analysis of genotype frequencies and allelic frequencies of two polymorphisms of SLC1A3 C3590T and SLC1A3 
Table 1 Primers used for detecting SNPs in BDNF and SLC1A3 gene with optimized temperatures and product size

\begin{tabular}{|c|c|c|c|c|}
\hline \multirow[t]{2}{*}{ Gene } & \multicolumn{2}{|l|}{ Primers } & \multirow{2}{*}{$\begin{array}{l}\text { Annealing } \\
\text { Temp }\end{array}$} & \multirow{2}{*}{$\begin{array}{l}\text { Product } \\
\text { size }\end{array}$} \\
\hline & Forward & Reverse & & \\
\hline$B D N F$ & 5'AAAGAAGCAAACATCCGAGGACAA3' & 5'ATTCCTCCAGCAGAAAGAGAAGAGG3' & $61^{\circ} \mathrm{C}$ & 274 \\
\hline SLC1A3 C3590T (3'UTR) & 5'TGGAGTGGGGTTGCTITTG3' & 5'GCCAGAAACTCAAACACAGC3' & $60^{\circ} \mathrm{C}$ & 232 \\
\hline SLC1A3 G869C (Coding region) & 5'ATTTCTGTGGACTAGCTTGGTG3' & 5'TTACCAAGAAGTAGAGGAGTGGC3' & $63^{\circ} \mathrm{C}$ & 223 \\
\hline
\end{tabular}

G869C and single polymorphism of BDNF G196A, in cases and controls were done separately, to test whether the genotypes are in Hardy-Weinberg equilibrium or not ( $p$ value $>0.05$ ). For statistical significance between genotypic and allelic distribution, Chi-square test and correlation matrix, were calculated between various factors. The analysis was done in the form of frequency tables, contingency table analysis using SPSS version 20 $\left(\mathrm{IBM}^{\oplus}\right.$, Armonk, NY, USA). Odds ratio was calculated to describe the (approximate) increase in risk associated with the non-reference genotype compared to the reference genotype and 95\% confidence interval (CI) was computed using GraphPadInStat version 3.0. Throughout analysis, $p$ value of $<0.05$ was taken to be statistically significant.

\section{Results}

Association of SLC1A3 C3590T (rs 2269272) polymorphism with stress and depression

The amplicon of SLC1A3 covering C3590T after digestion with the restriction endonuclease, $P f l \mathrm{~F} 1$, produce two fragments of DNA of $157 \mathrm{bp}$ and $75 \mathrm{bp}$. But a substitution of $\mathrm{T}$ in place of $\mathrm{C}$, causes loss of restriction site and thus single band of (full sized amplicon) 232 bp is obtained. Heterozygotes, on the other hand, shows three bands of 232, 157 and 75 bp (Fig. 1). Table 3 summarizes genotypic distribution of SLC1A3 C3590T in both cases and controls. Statistically significant difference was observed between cases and controls where the frequencies of CC, CT, TT were 46.3, 50.9 and 2.8\%, respectively, for cases and 63.4, 33.7 and $2.9 \%$, respectively, for controls $\left(p=0.0115, \mathrm{x}^{2}=\right.$ 8.934). The genotypic distribution in different groups according to three different models of association were analyzed, out of which significant differences in genotypic distributions was exhibited by dominant (CT + TT vs. CC) $\left(p=0.0052, X^{2}=7.796\right)$ and co-dominant models (CT vs. CC) $\left(p=0.0042, \chi^{2}=8.205\right)$, whereas the $p$ value obtained in the recessive model by Fisher exact test (TT vs. CT + CC) $(p=1.0000)$ and additive model (TT vs. CC) $(p=$ 0.7122 ) were not significant. Following the co-dominant model, the CT genotype showed two folds higher risk of developing stress and depression $(\mathrm{OR}=2.072$, CI $1.28-$ 3.35) compared to the CC genotype, while, the dominant model showed that the CT and TT genotype collectively imposed two times higher risk of stress compared to the CC genotype (OR = 2.011, CI 1.25-3.23). However, distribution of $\mathrm{C}$ and $\mathrm{T}$ alleles in cases and controls were significantly different ( $\mathrm{C}$ allele 0.72 in cases vs 0.80 in control and T allele 0.28 in cases vs 0.20 in control) as depicted in Table $3\left(p=0.0159, x^{2}=5.807\right)$. The SLC1A3 C3590T is not in Hardy-Weinberg equilibrium, indicating that the allele frequency may increase or decrease with time.

\section{SLC1A3 C869G (rs137852619) polymorphism analysis in stress and depression}

In SLC1A3 C869G, the amplicon normally has 'G' at 869th position which is not recognized by restriction endonuclease, Bst $\mathrm{U} 1$ and the full amplicon of $223 \mathrm{bp}$ is expected after electrophoresis. But if ' $C$ ' is substituted in place of $G$, then a restriction site is created and 2 bands of 152 and $71 \mathrm{bp}$ size are obtained; and the heterozygote shows three bands of 223, 152 and $71 \mathrm{bp}$. This polymorphism was not found in the present population under study so a full length amplicon of 223 bp was obtained (Fig. 2).

Table 2 Amplicon size, restriction endonucleases used and allele wise expected size of fragments after restriction digestion for the three SNPs studied

\begin{tabular}{|c|c|c|c|}
\hline SNP & Expected amplicon size (bp) & Restriction endonuclease used & Allele-wise expected fragment size (bp) \\
\hline $\begin{array}{l}\text { BDNF G196A } \\
\text { (rs 6265) }\end{array}$ & 274 & 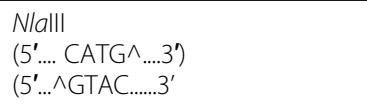 & $\begin{array}{l}\mathrm{GG}=216,58 \\
\mathrm{GA}=216,139,77,58 \\
\mathrm{AA}=139,77,58\end{array}$ \\
\hline $\begin{array}{l}\text { SLC1A3 C3590T } \\
\text { (rs 2269272) }\end{array}$ & 232 & $\begin{array}{l}\text { PfIF1 } \\
\left(5^{\prime} . . G A C N \wedge N N G T C . .3^{\prime}\right) \\
\left(3^{\prime} . . C T G N N \wedge N C A G . .5^{\prime}\right)\end{array}$ & $\begin{array}{l}C C=157,75 \\
C T=232,157,75 \\
\Pi=232\end{array}$ \\
\hline $\begin{array}{l}\text { SLC1A3 G869C } \\
\text { (rs 137852619) }\end{array}$ & 223 & $\begin{array}{l}\text { BstU1 } \\
\left(5^{\prime} . . C G \wedge C G .3^{\prime}\right) \\
\left(3^{\prime} . . G C \wedge G C . .5^{\prime}\right)\end{array}$ & $\begin{array}{l}\mathrm{GG}=223 \\
\mathrm{GC}=223,152,71 \\
\mathrm{CC}=152,71\end{array}$ \\
\hline
\end{tabular}

\footnotetext{
$\wedge$ represent the recognition site
} 


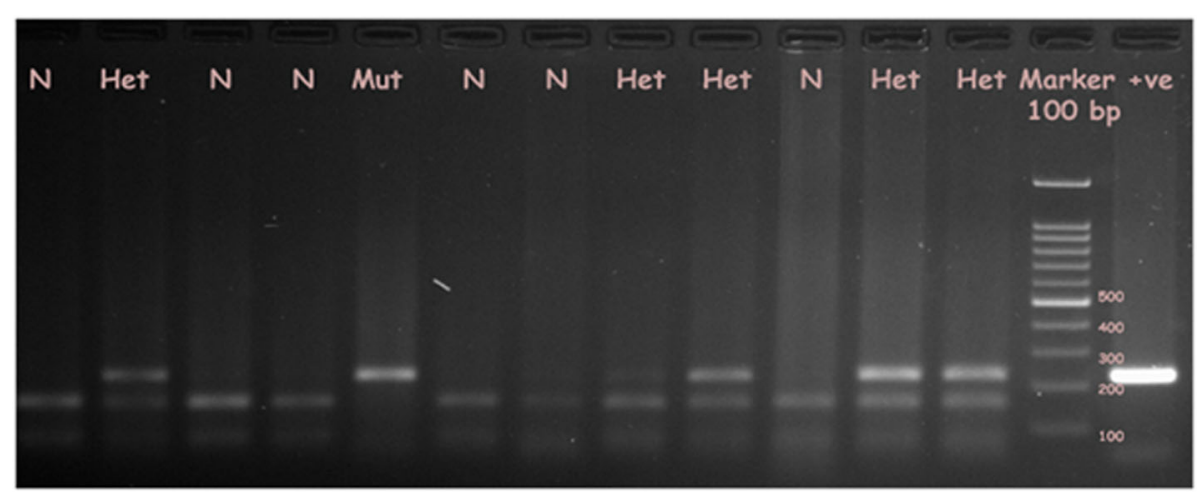

Fig. 1 Restriction digestion by PfIF1 of SLC1A3 C3590T amplicon of representative individuals. The amplicon of SLC1A3 C3590T after digestion with the restriction endonuclese, PfF 1 , in normal condition (i.e when $C$ is present at 3590 position) shows two fragments of DNA, 157 and 75 bp (lane $1,3,4,6,7,10)$. A substitution of $\mathrm{T}$ in place of $\mathrm{C}$, causes loss of restriction site and only one band of $232 \mathrm{bp}$ (full sized amplicon; lane 5) is obtained. Heterozygotes on the other hand shows three bands of 232, 157 and 75 bp (lane 2, 8, 9, 11, 12)

\section{Association of BDNF G196A (rs6265) polymorphism with} stress and depression

The genotypic distribution of BDNF G196A in both cases with stress and depression and normal controls is as shown in Table 4. BDNF G196A normally has G at 196th position which is not recognised by its restriction enzyme (Nla III) and cuts at 273rd position forming normal signal peptide and mature BDNF (two fragments amplicon 216 and $58 \mathrm{bp}$ ). But when there is substitution of A at 196 position, a new restriction site is created, therefore cut position is at 196th and 273rd positions producing 139, 77 and 58 bps fragments. Heterozygotes having both types of allele shows four fragments of 216 , 139, 77 and 58 bps (Fig. 3). Hardy Weinberg equilibrium was calculated for BDNF G196A was found to be in equilibrium. The allelic frequencies showed uniformity in both cases and controls ( $\mathrm{G}$ allele 0.80 in cases vs 0.79 in control and A allele 0.20 in cases vs 0.21 in control).
Our data revealed lack of significant differences in GG, GA, AA: $64.8,30.6$ and $4.6 \%$, respectively, for cases and $63.4,31.2$ and $5.4 \%$, respectively, for controls. The distribution of the $\mathrm{G}$ and $\mathrm{A}$ alleles in cases and controls was not significantly different showing no association with stress and depression as depicted in Table $4(p=0.7534$, $\left.X^{2}=0.0987\right)$.

\section{Discussion}

The present study focuses on association of SLC1A3 C3590T, C869G and BDNF G196A in case control studies with stress and depression in an eastern Indian population. Association with stress and depression was observed only in T allele of SLC1A3 C3590T in a cohort from an eastern region of India (eastern Uttar Pradesh), suggesting that the minor allele (T) in SLC1A3 C3590T may contribute to the risk of stress and depression together.

Table 3 Genotypic distribution of SLC1A3 C3590T (rs 2,269,272) in relation with Stress and Depression

\begin{tabular}{|c|c|c|c|c|c|}
\hline Genotype/Allele frequency & Cases $(N=108)$ & Controls $(N=205)$ & $p\left(x^{2}\right)$ & Odds ratio (OR) & 95\% Confidence Interval (Cl) \\
\hline $\mathrm{CC}$ & $50(46.3 \%)$ & $130(63.4 \%)$ & \multirow[t]{3}{*}{$0.0115(8.934)^{*}$} & & \\
\hline$C T$ & $55(50.9 \%)$ & $69(33.7 \%)$ & & & \\
\hline$\pi$ & $3(2.8 \%)$ & $6(2.9 \%)$ & & & \\
\hline \multicolumn{3}{|c|}{ Linear by linear association (Armitage tests for trends) } & \multicolumn{2}{|l|}{$0.010^{*}$} & \\
\hline \multicolumn{3}{|c|}{ Dominant Model (CT + TT vs. CC) } & $0.0052(7.796)^{*}$ & 2.011 & $1.25-3.23$ \\
\hline \multicolumn{3}{|c|}{ Co- dominant Model (CT vs. CC) } & $0.0042(8.205)^{*}$ & 2.072 & $1.28-3.35$ \\
\hline \multicolumn{3}{|c|}{ Recessive Model (TT vs. CT + CC) } & 1.0000 & 0.948 & $0.23-3.87$ \\
\hline \multicolumn{3}{|l|}{ Additive Model (TT vs. CC) } & 0.7122 & 1.300 & $0.31-5.40$ \\
\hline \multicolumn{6}{|l|}{ Allele frequency distribution } \\
\hline Alleles & Cases & Controls & \multicolumn{3}{|l|}{$p\left(x^{2}\right)$} \\
\hline C & $155(0.72)$ & $329(0.80)$ & \multicolumn{3}{|l|}{$0.0159(5.807)^{*}$} \\
\hline $\mathrm{T}$ & $61(0.28)$ & $81(0.20)$ & & & \\
\hline
\end{tabular}

The table represents the genotypic frequency, the allelic frequency as well as odds - ratio for different models. Number of participants $(n)=313$

* indicates $p<0.05$ 


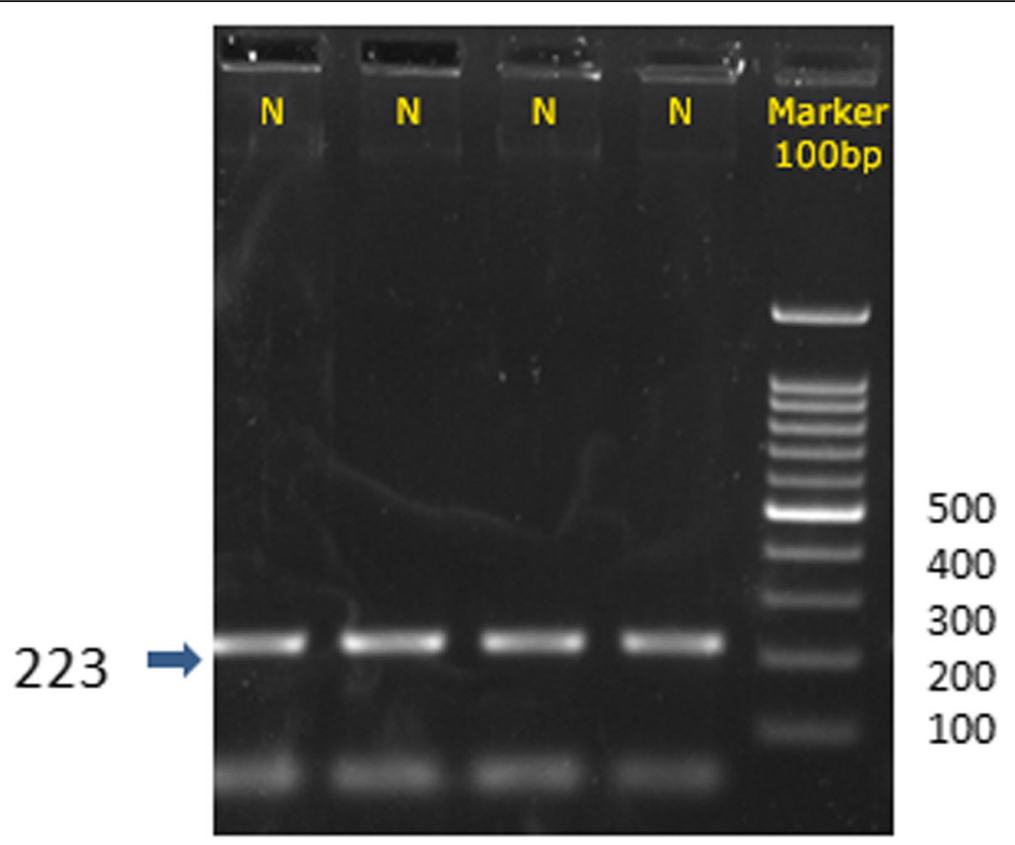

Fig. 2 Restriction digestion by BstU1 of SLC1A3 C869G amplicon of representative individuals. This polymorphism was not found in the cohort of individuals selected and a full length amplicon of $223 \mathrm{bp}$, is seen in all the lanes. The cases and controls with reference to stress and depression showed no heterozygotes in control as well cases

SLC1A3 gene in normal condition makes a protein called excitatory amino acid transporter 1 (EAAT1) expressed on mainly astrocyte membrane and involved in regulating excess glutamate concentration, which is found in synaptic spaces after synaptic transmission. EAAT1 is found throughout the brain, most abundantly in parts in connection to spinal cord (brain stem) and cerebellum (co-ordinates movements).

Since SLC1A3 forms a glial high-affinity glutamate transporter (GLAST) molecule regulating glutamate concentration after synaptic transmission, its anomalous expression may impair reuptake of glutamate, leading to prolonged synaptic activation and cytotoxicity in neurons and glial [40]. On the other hand as stated above, SLC1A3 is down-regulated in MDD (Major depressive disorder) patients, also reduced expression of SLC1A3 gene has been observed in suicidal behaviour [41, 42]. In the present study, 3'UTR polymorphism (C3590T) is associated with stress as well as depression. Frequencies of CC genotype of SLC1A3 C3590T were significantly higher in controls (63.4\%) than in cases $(46.3 \%)$. Calculations based on dominant model in Table 3 revealed that individuals with the CT and TT genotypes collectively showed more than two folds higher risk of developing stress and depression compared to those with CC genotype. Also, similar evidence is found from the codominant model, where CT genotype confers 2.072 fold higher risk of developing stress. Table 3 also shows that the frequency of $\mathrm{C}$ allele is much lower in cases (0.72) than in controls $(0.80)$. The frequency of TT genotype

Table 4 Genotypic distribution of BDNF G196A (rs6265) in relation with stress and depression (case) and unstressed (control)

\begin{tabular}{llll}
\hline Genotype/Allele frequency & Cases $(N=108)$ & Controls $(N=205)$ & $p\left(X^{2}\right)$ \\
\hline GG & $70(64.8 \%)$ & $130(63.4 \%)$ & $0.9480(0.1068)$ \\
GA & $33(30.6 \%)$ & $64(31.2 \%)$ & $11(5.4 \%)$ \\
AA & $5(4.6 \%)$ & & 0.760 \\
Linear by linear association (Armitage tests for trends) & & $p\left(X^{2}\right)$ \\
Allele frequency distribution & & Controls & $0.7534(0.0987)$ \\
Alleles & Cases & $324(0.79)$ & $86(0.21)$ \\
G & $173(0.80)$ & & \\
A & $43(0.20)$ & & \\
\hline
\end{tabular}

The table represents the genotypic frequency and the allelic frequency for different models. $(N=313)$ 


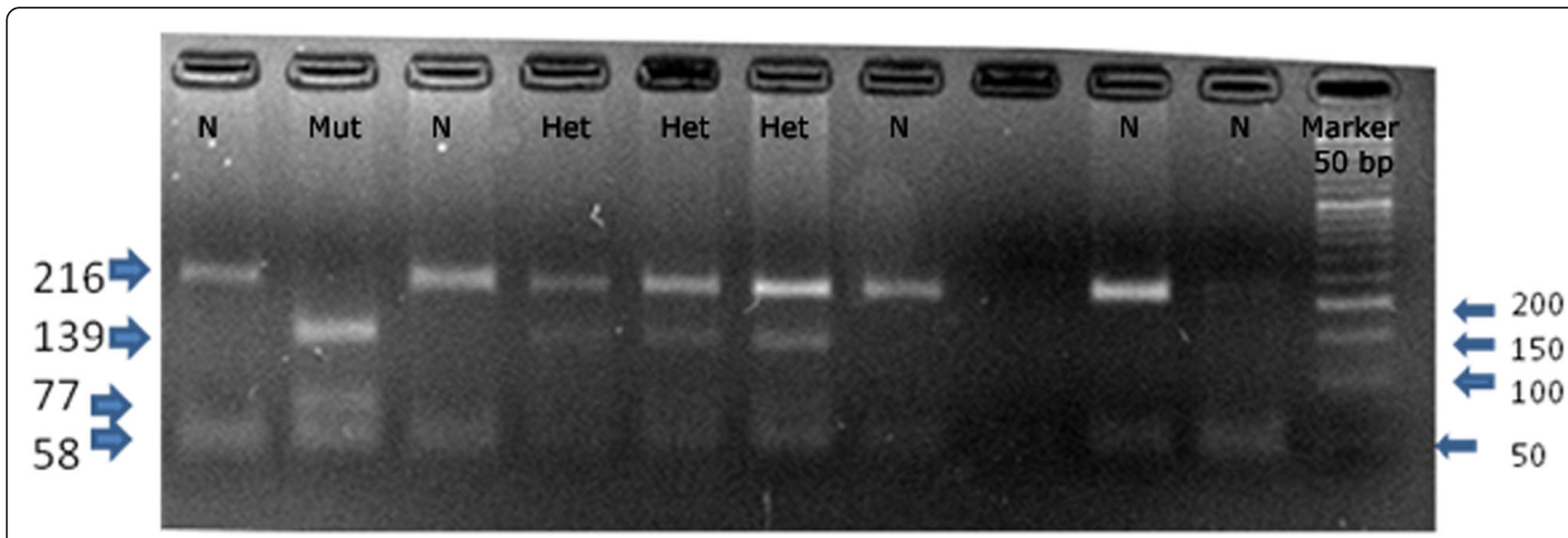

Fig. 3 Restriction digestion of BDNF G196A amplicon by Nlall of representative individuals. The amplicon after digestion in normal condition (i.e. in presence of major allele G) N = major allele (homozygotes) which gives two bands of 216 and 58 bp (Lane 1, 3, 7, 9, 10); A substitution of A in place of G creates new restriction site, so Mut = minor allele (homozygotes) giving three bands of 139, 77 and 58 bp (lane 2) and Heterozygotes having both types of alleles forms 4 bands Het = heterozygotes, which give four bands of 216, 139, 77 and 58 bp (lane 4, 5, 6)

and the minor allele frequency (MAF) of T allele (0.20) in our control group are also similar to those reported in previous studies with reference to depression and in other psychiatric disorders conducted in different populations $[16,43]$. However, the frequencies of the CC genotype and $\mathrm{C}$ allele are lower in cases than in the control group and this is the first report of this polymorphism in Indian population. It can be hypothised that the 3'UTR polymorphism may decrease protein translation without change in protein conformation.

SLC1A3 C869G, a missense SNP, is known to be pathogenic and mutation in this gene has been found to cause episodic ataxia type 6 [44]. This change from $C$ to G, replacing amino acid proline to arginine at 290 position (P290R), impairs EAAT1 to remove glutamate from synaptic cleft. This impairment may overexcite certain neurons disrupting normal communication within neurons, which is visualised as uncoordinated movement in individuals with episodic ataxia. But the molecular mechanism in this is unknown, however in the present study SLC1A3 C869G was not found to be associated with either stress or depression.

In a study by Bechtholt-Gompf [10] on rats it was shown that disruption of glutamate uptake from the synapse was linked to reduced sensitivity to reward, showing symptoms of depression. In another study on human autopsy samples, it was found that AMPA receptors (glutamate receptor) in anterior cingulated cortex were increased in major depressive disorder [45]. In an animal model study it was found that, mice knockout for AMPA subunit-1 showed higher helplessness, decrease in serotonin and nor-epinephrine levels and disturbed glutamate homeostasis. All these results establish that deregulated glutamate homeostasis leads to disruption of many functions and may lead to depression, too.
A support of our observation comes from a family based study by Turic et al. in 2005 conducted on Caucasian samples, that found significant association of $\mathrm{T}$ allele of SLC1A3 (C3590T) with attention deficit hyperactivity disorder (ADHD) [43]. The association of the same polymorphism was also later shown by Murphy et al. [16] in suicidal victims where SLC1A3 expression was shown to be highly reduced [15]. In the present study the ' $\mathrm{T}$ ' allele was associated with stress and depression, whereas the $\mathrm{C}$ allele (major allele) acts as a protective allele. Therefore, it could be speculated that like in suicidal victims, in the above study also due to presence of $\mathrm{T}$ allele, the expression of the gene was reduced predisposing the individuals for stress and/or depression. On the other hand a study done on samples from South Korea on mood disorder by Choi et al. [46], did not find association of suicidal behaviour with this polymorphism.

$B D N F$ is the most studied gene, which is shown to be associated with many different mental disorders and is known to interact with various developmental pathways [47]. The trafficking and localization of BDNF appears to be controlled by its pro-domain. A SNP in the prodomain of BDNF, converts the 66th amino acid valine into methionine (Val66Met) which affects dendritic trafficking and synaptic localization of BDNF as well as impairs its secretion. Human subjects carrying the Val66Met SNP exhibit deficits in short-term episodic memory and show abnormal hippocampal activation.

$B D N F$ G196A polymorphism reduces the expression of the gene and activates apoptotic pathway $[48,49]$ and in other populations as US Caucasians, American Indian, African American, Chinese a significant association of this polymorphism was shown with depression cases [50-52] and several psychiatric disorders such as anxiety, obsessive compulsive disorder, depression, 
schizophrenia, psychosis and eating disorder [36, 53]. BDNF G196A, "A" (minor allele) has been considered as the risk factor because this minor allele carriers have a reduced activity dependent secretion of $\operatorname{BDNF}[29,54]$. However $\mathrm{G}$ allele (major allele) has been reported to be associated with bipolar disorder $[55,56]$ and substance use $[57,58]$ with increased BDNF activity [59-62]. Also, in Mexican- American population GG genotype (Val homozygote) has been found to be associated with increased chance of depression [63]. A meta-analysis on different ethnic groups performed by Li et al. [31] found significant association of $\mathrm{G}$ allele with bipolar in Europeans but not in Asians. And allele A carriers show an increased propensity towards Parkinson's disease in Europeans but not in Asians. However, a positive association was found with suicidal behaviour in Asians, Caucasians but not in Europeans. But contrary to this, in the present study no association of G196A was found with stress and depression. In the present study, interestingly the frequencies of AA (minor allele of $B D N F$ G196A) was more in controls than in cases, however the $X^{2}=0.0987$ was not significant, although, it is known that BDNF G196A allele A have a variable frequency ranging between $0 \%$ in Africa upto $72 \%$ in Asia [30]. This allelic frequency distribution in eastern Indian population may be of significance and needs a wider study. Further GWAS studies in recent years have identified several genetic loci but did not find any association of $B D N F$ G196A with stress and depression [29].

\section{Conclusion}

We conclude that SLC1A3 C3590T (rs2269272) polymorphism is associated with stress and depression in eastern Indian population studied $(p=0.0042, \mathrm{OR}=$ 2.072). This allele increases the risk by two folds for stress and depression in the present population, therefore presence of this allele in an individual may predict the development of stress and depression in future. This knowledge may also help in development of drug for those having this allele and may also help in the understanding of pathophysiology of the disease and identification of better drug.

\footnotetext{
Abbreviations

BDNF: Brain derived neurotrophic factor; SLC1A3: Solute Carrier Family 1 Member 3 (sodium dependent, high affinity amino acid transporter): PSS: Percieved stress scale; CES-D: Center for epidemiologic Studies Depression; PCR: Polymerase Chain Reaction; SNP: Single Nucleotide polymorphism; SLC1: Solute Carrier Family 1 (glutamate/neutral aminoacid transporter family); EAAT: Excitatory amino acid transporters; AMPA: a-amino3-hydroxy-5-methyl-4-isoxazole propionic acid (glutamate receptor); NMDA: N-methyl-D-aspartate receptor (inotropic glutamate receptor); GWAS: Genome-Wide Association Studies; tSNARE1: t-SNARE domain containing 1; SLC1A2: Solute Carrier Family 1 Member 2 (glial glutamate transporter); SLC17A7: Solute Carrier Family 17 Member 7 (sodium dependent inorganic phosphate co-transporter); UTR: Untranslated region; Val66Met: Valine to methionine at codon 66; Met: Methionine; Val: Valine; DSM-5: Diagnostic and Statistical Manual of Mental Disorders, 5th edition;
}

${ }^{\circ} \mathrm{C}$ : Degree Celcius; $\mu$ l: microliter; rpm: revolutions per minute; min: minute; sec: second; SDS: Sodium dodecyl sulfate; DNA: Deoxyribonucleic acid; EDTA: Ethylene diamine tetra acetic acid; BLAST: Basic Local Alignment Search Tool; SPSS: Statistical Package for the Social Sciences; Cl: Confidence interval; OR: Odds ratio; bp: base pairs; GLAST: Glial high-affinity glutamate transporter; MDD: Major depressive disorder; MAF: Minor allele frequency: ADHD: Attention deficit hyperactivity disorder

\section{Acknowledgements}

We thank Dr. Dau Dayal, a member of our Lab, for his help in preparation of the manuscript, to Dr. Rajiva Raman for discussions at greater depths and to Mr. Anurag, Department of Statistics, for his help in statistical analysis. We also thank all the doctors in the Psychiatry Department who taught MG to handle the patients during sample collection. The CAS in Zoology is acknowledged for fellowship to MG; UGC-UPE and DST-FIST for equipment facilities in Zoology.

\section{Authors' contributions}

MG collected samples, conducted experiments and drafted the manuscript. $\mathrm{AA}$, the human geneticist, helped throughout in the project and in trouble shooting as well as interpretation of data. SJ, a professor from Psychology, helped in selecting the questionnaires and in personal data bank preparation, and also provided personal as well as professional assistance during the course of the study. ASS, a psychiatrist, who allowed MG to the clinic for patient samples collections. MGT, Ph. D supervisor, guided MG, provided all the facilities and helped in preparation of the manuscript and revised substantially. The author(s) read and approved the final manuscript.

\section{Funding}

UGC-CAS of Department of zoology, BHU provided research fellowship to $M G$

\section{Availability of data and materials}

The data sets analysed throughout the present study are available in the NCBI database (https://www.ncbi.nlm.nih.gov/). The dataset(s) supporting the conclusions of this article is included within the article.

\section{Ethics approval and consent to participate}

The study was approved by the Institutional Ethical Committee of Banaras Hindu University, prior to initiation of study. Informed written consent was obtained from each of the participant and their parents for the study. The Consent was also taken from the principals of the schools from which the participants were involved.

\section{Consent for publication}

Not applicable.

\section{Competing interests}

The authors declare that they have no competing interests.

\section{Author details}

'Cytogenetics Laboratory, Department of Zoology, Banaras Hindu University, Varanasi 221005, India. ${ }^{2}$ Centre for Genetic Disorders, Faculty of Science, Banaras Hindu University, Varanasi 221005, India. ${ }^{3}$ Department of Psychology, Faculty of Arts, Banaras Hindu University, Varanasi 221005, India. ${ }^{4}$ Department of Psychiatry, Institute of Medical Sciences, Banaras Hindu University, Varanasi 221005, India.

Received: 31 October 2019 Accepted: 4 March 2020

Published online: 14 March 2020

\section{References}

1. Selye H. A syndrome produced by diverse nocuous agents. Nature. 1936; 138:32. https://doi.org/10.1176/jnp.10.2.230a.

2. Khan S, Khan RA. Chronic stress leads to anxiety and depression. Ann Psychiatry Mental Health. 2017;5:1091.

3. Santrock JW. Adolescence. McGraw Hill 11th Ed; 2007.

4. Sullivan PF, Neale MC, Kendler KS. Genetic epidemiology of major depression: review and meta-analysis. Am J Psychiatry. 2000;157:1552-62. https://doi.org/10.1176/appi.ajp.157.10.1552. 
5. Kendler KS, Gardner CO, Neale MC, Prescott CA. Genetic risk factors for major depression in men and women: similar or different heritabilities and same or partly distinct genes. Psychol Med. 2001;31:605-16. https://doi.org/ 10.1017/s0033291701003907.

6. Kendler KS, Gatz M, Gardner CO, Pedersen NL. A Swedish national twin study of lifetime major depression. Am J Psychiatry. 2006;163:109-14. https://doi.org/10.1176/appi.ajp.163.1.109.

7. Kristensen AS, Andersen J, Jorgensen TN, Sorensen L, Eriksen J, Loland CJ, et al. SLC6 neurotransmitter transporters: structure, function and regulation. Pharmacol Rev. 2011;63:585-640. https://doi.org/10.1124/pr.108.000869.

8. Rothman DL, Behar KL, Hyder F, Shulman RG. In vivo NMR studies of the glutamate neurotransmitter flux and neuroenergetics: implications for brain function. Annu Rev Physiol. 2003;65:401-27. https://doi.org/10.1146/annurev. physiol.65.092101.142131.

9. Mathews DC, Henter ID, Zarate CA Jr. Targeting the glutamatergic system to treat major depressive disorder: rationale and progress to date. Drugs. 2012; 72:1313-33. https://doi.org/10.2165/11633130-000000000-00000.

10. Bechtholt-Gompf AJ, Walther HV, Adams MA, Carlezon WA Jr, Ongur D, Cohen BM. Blockade of astrocytic glutamate uptake in rats induces signs of anhedonia and impaired spatial memory. Neuropsychopharmacol. 2010;35: 2049. https://doi.org/10.1038/npp.2010.74.

11. Ripke S, Wray NR, Lewis CM, Hamilton SP, Weissman MM, Breen G, et al. A mega-analysis of genome-wide association studies for major depressive disorder. Mol Psychiatry. 2013;18:497-511. https://doi.org/10.1038/mp.2012.21.

12. Sleiman P, Wang D, Glessner J, Hadley D, Gur RE, Cohen N, et al. GWAS meta analysis identifies tSNARE1 as a novel schizophrenia/bipolar susceptibility locus. Sci Rep. 2013;3:3075. https://doi.org/10.1038/srep03075.

13. Su PH, Gasic M, Mrksic N, Rojas-Barahona L, Ultes S, Vandyke D, et al. Continuously learning neural dialogue management. arXiv preprint arXiv: 1606.02689. 2016.

14. O'Dushlaine C, Kenny E, Heron E, Donohoe G, Gill M, Morris D, et al. Molecular pathways involved in neuronal cell adhesion and membrane scaffolding contribute to schizophrenia and bipolar disorder susceptibility. Mol Psychiatry. 2011;16:286-92. https://doi.org/10.1038/mp.2010.7.

15. Medina A, Burke S, Thompson RC, Bunney W Jr, Myers RM, Schatzberg A, et al. Glutamate transporters: a key piece in the glutamate puzzle of major depressive disorder. J Psychiatr Res. 2013;47:1150-6. https://doi.org/10.1016/ j.jpsychires.2013.04.007.

16. Murphy TM, Ryan M, Foster T, Kelly C, McClelland R, O'Grady J, Brown K. Risk and protective genetic variants in suicidal behaviour: association with SLC1A2, SLC1A3, 5-HTR1B and NTRK2 polymorphism. Behav Brain Func. 2011;7:22. https://doi.org/10.1186/1744-9081-7-22.

17. Kao CF, Fang YS, Zhao Z, Kuo PH. Priortization and evaluation of depression candidate genes by combining multi-dimentional data resources. PLoS One. 2011;6:e18696. https://doi.org/10.1371/journal.pone.0018696.

18. Duman RS. Pathophysiology of depression: the concept of synaptic plasticity. Eur Psychiatry. 2002;17(Suppl 3):306-10. https://doi.org/10.1016/ s0924-9338(02)00654-5.

19. Warner-Schmidt JL, Duman RS. Hippocampal neurogenesis: opposing effects of stress and antidepressant treatment. Hippocampus. 2006;16:23949. https://doi.org/10.1002/hipo.20156.

20. Neeley EW, Berger R, Koenig Jl, Leonard S. Prenatal stress differentially alters BDNF expression and signaling across rat strains. Neuroscience. 2011;187: 24-35. https://doi.org/10.1016/j.neuroscience.2011.03.065.

21. Huang EJ, Reichardt LF. Neurotrophins: roles in neuronal development and function. Ann Rev Neurosci. 2001;24:677-736. https://doi.org/10.1146/ annurev.neuro.24.1.677.

22. Lu B. Pro-region of neurotrophins: role in synaptic modulation. Neuron. 2003;39:735-8. https://doi.org/10.1016/s0896-6273(03)00538-5.

23. Notaras $M$, van den Buuse M. Neurobiology of BDNF in fear memory, sensitivity to stress, and stress-related disorders. Mol Psychiatry. 2020. https://doi.org/10.1038/s41380-019-0639-2.

24. Mandelman SD, Grigorenko EL. BDNF Val66Met and cognition: all, none, or some? A meta-analysis of the genetic association. Genes, Brain Behav. 2012; 11:127-36. https://doi.org/10.1111/j.1601-183X.2011.00738.x

25. Gonzalez-Castro TB, Salas-Magana M, Juarez-Rojop IE, Lopez-Narvaez ML, Tovilla-Zarate CA, Hernandez-Diaz Y. Exploring the association between BDNF Val66Met polymorphism and suicidal behavior: meta-analysis and systematic review. J Psychiatr Res. 2017;94:208-17. https://doi.org/10.1016/j. jpsychires.2017.07.020.
26. Egan MF, Kojima M, Callicott JH, Goldberg TE, Kolachanna BS, Bertolino A, et al. The BDNF Val66Met polymorphism affects activity-dependent secretion of BDNF and human memory and hippocampal function. Cell. 2003;112:257-69. https://doi.org/10.1016/s0092-8674(03)00035-7.

27. Shimizu E, Hashimoto K, lyo M. Ethnic difference of the BDNF 196G/a (val66met) polymorphism frequencies: the possibility to explain ethnic mental traits. Am J Med Genet B Neuropsychiatr Genet. 2004;126B:122-3. https://doi.org/10.1002/ajmg.b.20118.

28. Gyekis JP, Yu W, Dong S, Wang H, Qian J, Kota P. No association of genetic variants in BDNF with major depression: a meta- and gene-based analysis. Amm J Med Genet B Neuropsychiatr Genet. 2013;162B:61-70. https://doi. org/10.1002/ajmg.b.32122.

29. Tsai S-J. Critical issues in BDNF Val66Met genetic studies of neuropsychiatric disorders. Front Mol Neurosci. 2018;11:156. https://doi.org/10.3389/fnmol. 2018.00156

30. Petryshen TL, Sabeti PC, Aldinger KA, Fry B, Fan JB, Schaffner SF. Population genetic study of the brain-derived neurotrophic factor (BDNF) gene. Mol Psychiatry. 2010;15:810-5. https://doi.org/10.1038/mp.2009.24.

31. Li M, Chang H, Xiao X. BDNF Val66Met polymorphism and bipolar disorder in European populations: a risk association in case-control, family-based and GWAS studies. Neurosci Biobehav Rev. 2016;68:218-33. https://doi.org/10. 1016/j.neubiorev.2016.05.031.

32. Chan CB, Ye K. Sex differences in brain-derived neurotrophic factor signaling and functions. J Neurosci Res. 2017;95:328-35. https://doi.org/10. 1002/jnr.23863.

33. Wei SM, Baller EB, Kohn PD, Kippenhan JS, Kolachana B, Soldin SJ, et al. Brain-derived neurotrophic factor Val66Met genotype and ovarian steroids interactively modulate working memory-related hippocampal function in women: a multimodal neuroimaging study. Mol Psychiatry. 2017;23:106675. https://doi.org/10.1038/mp.2017.72.

34. Zhao M, Chen L, Yang J, Han D, Fang D, Qiu X, et al. BDNF Val66Met polymorphism, life stress and depression: a meta-analysis of geneenvironment interaction. J Affect Disord. 2017;227:226-35. https://doi.org/10. 1016/j.jad.2017.10.024.

35. Baker E, Schmidt KM, Sims R, O'donovan MC, Williams J, Holmans P, et al. POLARIS: polygenic LD-adjusted risk score approach for set-based analysis of GWAS data. Genet Epidemiol. 2018. https://doi.org/10.1002/gepi.22117.

36. Hong CJ, Liou YJ, Tsai SJ. Effects of BDNF polymorphisms on brain function and behavior in health and disease. Brain Res Bull. 2011;86:287-97. https:// doi.org/10.1016/j.brainresbull.2011.08.019..

37. Cohen S, Kamarck T, Mermelstein R. A global measure of perceived stress. J Health Soc Behav. 1983;24:386-96. https://doi.org/10.2307/2136404.

38. Radloff LS. The CES-D scale: a self-report depression scale for research in the general population. Appl Psychol Meas. 1977;1:385-401. https://doi.org/10. 1177/014662167700100306.

39. American Psychiatric Association. Diagnostic and statistical manual of mental disorders. Fifth ed. Arlington: American Psychiatric Publishing, Inc.; 2013. https://doi.org/10.1176/appi.books.9780890425596.744053.

40. Choudary PV, Molnar M, Evans SJ, Tomita H, Li JZ, Vawter MP, et al. Altered cortical glutamatergic and GABAergic signal transmission with glial involvement in depression. Proc Natl Acad Sci U S A. 2005;102:15653-8. https://doi.org/10.1073/pnas.0507901102.

41. Coyle JT, Schwarcz R. Mind glue: implications of glial cell biology for psychiatry. Arch Gen Psychiatry. 2000;57:90-3. https://doi.org/10.1001/ archpsyc.57.1.90.

42. Kim S, Choi KH, Baykiz AF, Gershenfeld HK. Suicide candidate genes associated with bipolar disorder and schizophrenia: an exploratory gene expression profiling analysis of post-mortem prefrontal cortex. BMC Genomics. 2007:8:413. https://doi.org/10.1186/1471-2164-8-413.

43. Turic D, Langley K, Williams $H$, Norton N, Williams NM, Moskvina V, et al. A family based study implicates solute carrier family 1-member 3 (SLC1A3) gene in attentiondeficit/hyperactivity disorder. Biol Psych. 2005;57:1461-6. https://doi.org/10.1016/j.biopsych.2005.03.025.

44. Hotzy J, Schneider N, Kovermann P, Fahlke C. Mutating a conserved proline residue within the trimerization domain modifies $\mathrm{Na}+$ binding to excitatory amino acid transporters and associated conformational changes. J Biol Chem. 2013;288:36492-501. https://doi.org/10.1074/jbc. M113.489385.

45. Gibbons RD, Hur K, Brown CH, Davis JM, Mann JJ. Benefits from antidepressants: synthesis of 6-week patient-level outcomes from doublebling placebo-controlled randomized trials of fluoxetine and venlafaxine. 
Arch Gen Psych. 2012;69:572-9. https://doi.org/10.1001/archgenpsychiatry. 2011.2044.

46. Choi HY, Kim GE, Kong KA, Lee YJ, Lim WJ, Park SH, et al. Psychological and genetic risk factors associated with suicidal behavior in Korean patients with mood disorders. J Affect Disord. 2018;235:489-98. https://doi.org/10.1016/j. jad.2018.04.059.

47. Maheu ME, Ressler KJ. Developmental pathway genes and neural plasticity underlying emotional learning and stress-related disorders. Learn Mem. 2017;24:492-501. https://doi.org/10.1101/lm.044271.116.

48. Gentry JJ, Barker PA, Carter BD. The p75 neurotrophin receptor: multiple interactors and numerous functions. Prog Brain Res. 2004;146:25-39. https:// doi.org/10.1016/50079-6123(03)46002-0.

49. Teng HK, Teng KK, Lee R, Wright S, Tevar S, Almeida RD, Kraemer RT. ProBDNF induces neuronal apoptosis via activation of a receptor complex of p75NTR and sortilin. J Neurosci. 2005;25:5455-63. https://doi.org/10.1523/ JNEUROSCI.5123-04.2005.

50. Jiang X, Xu K, Hobabman J, Tian F, Marko AJ, Waheed JF, et al. BDNF variation and mood disorders: a novel functional promoter polymorphism and Val66Met are associated with anxiety but have opposing effects. Neuropsychopharmacol. 2005;30:1353. https://doi.org/10.1038/sj.npp. 1300703.

51. Chen ZY, Jing D, Bath KG, leraci A, Khan T, Siao CJ, et al. Genetic variant BDNF (Val66Met) polymorphism alters anxiety-related behaviour. Science. 2006;314:140-3. https://doi.org/10.1126/science.1129663.

52. Hwang JP, Tsai SJ, Hong CJ, Yang CH, Lirng JF, Yang YM. The Val66Met polymorphism of the brain-derived neurotrophic-factor gene is associated with geriatric depression. Neurobiol Ageing. 2006;27:1834-7. https://doi.org/ 10.1016/j.neurobiolaging.2005.10.013.

53. Notaras M, Hill R, Van Den BM. The BDNF gene Val66Met polymorphism as a modifier of psychiatric disorder susceptibility: progress and controversy. Mol Psychiatry. 2015;20:916-30. https://doi.org/10.1038/mp.2015.27.

54. Jin P, Andiappan AK, Quek JM, Lee B, Au B, Sio YY, et al. A functional brainderived neurotrophic factor (BDNF) gene variant increases the risk of moderate-to-severe allergic rhinitis. J Allergy Clin Immunol. 2015;135:1486. e8-93.e8. https://doi.org/10.1016/j.jaci.2014.12.1870.

55. Neves-Pereira M, Mundo E, Muglia P, King N, Macciardi F, Kennedy JL. The brain derived neurotrophic factor gene confers susceptibility to bipolar disorder: evidence from a family-based association study. Amm J Hum Genet. 2002;71:651-5. https://doi.org/10.1086/342288.

56. Sklar P, Gabriel SB, Mcinnis MG, Bennett P, Lim Y, Tsan G. Family-based association study of 76 candidate genes in bipolar disorder: BDNF is a potential risk locus. Mol Psychiatry. 2002;7:579-93. https://doi.org/10.1038/sj. mp.4001058.

57. Cheng CY, Hong CJ, Yu YW, Chen TJ, Wu HC, Tsai SJ. Brain-derived neurotrophic factor (Val66Met) genetic polymorphism is associated with substance abuse in males. Brain Res Mol Brain Res. 2005;140:86-90. https:// doi.org/10.1016/j.molbrainres.2005.07.008.

58. Sim MS, Mohamed Z, Hatim A, Rajagopal VL, Habil MH. Association of brainderived neurotrophic factor (Val66Met) genetic polymorphism with methamphetamine dependence in a Malaysian population. Brain Res. 2010; 1357:91-6. https://doi.org/10.1016/j.brainres.2010.08.053.

59. Tsai SJ. Is autism caused by early hyperactivity of brain-derived neurotrophic factor? Med. Hypotheses. 2005;65:79-82. https://doi.org/10.1016/..mehy. 2005.01.034.

60. Tsai SJ. TrkB partial agonists: potential treatment strategy for epilepsy, mania, and autism. Med Hypotheses. 2006;66:173-5. https://doi.org/10.1016/ j.mehy.2005.05.033.

61. Tsai SJ. TrkB partial agonists: potential treatment strategy for major depression. Med Hypotheses. 2007;68:674-6. https://doi.org/10.1016/j.mehy. 2006.06.019.

62. Ilchibaeva TV, Tsybko AS, Kozhemyakina RV, Kondaurova EM, Popova NK, Naumenko VS. Genetically defined fear-induced aggression: focus on BDNF and its receptors. Behav Brain Res. 2018;343:102-10. https://doi.org/10.1016/ j.bbr.2018.01.034.

63. Ribeiro L, Busnello JV, Cantor RM, Whelan F, Whittaker P, Deloukas P. The brain derived neurotrophic factor rs6265 (Val66Met) polymorphism and depression in Mexican-Americans. Neuro Report. 2007;18:1291-3. https://doi. org/10.1097/WNR.0b013e328273bcb0

\section{Publisher's Note}

Springer Nature remains neutral with regard to jurisdictional claims in published maps and institutional affiliations.

\section{Ready to submit your research? Choose BMC and benefit from:}

- fast, convenient online submission

- thorough peer review by experienced researchers in your field

- rapid publication on acceptance

- support for research data, including large and complex data types

- gold Open Access which fosters wider collaboration and increased citations

- maximum visibility for your research: over $100 \mathrm{M}$ website views per year

At BMC, research is always in progress.

Learn more biomedcentral.com/submissions 